\title{
An Alternative Explanation of the Price Puzzle
}

\author{
Paolo Giordani*
}

\begin{abstract}
This paper proposes a simple explanation for the frequent appearance of a price puzzle in VARs designed for monetary policy analysis. It suggests that the best method of solving the puzzle implies a close connection between theory and empirics rather than the introduction of a commodity price. It proves that the omission of a measure of output gap (or potential output) spuriously produces a price puzzle (and several other incorrect conclusions) in a wide class of commonly used models. This can happen even if the model admits a triangular identification and if the forecasts produced by the misspecified VAR are optimal. When the model is tested on US data, all predictions are supported.
\end{abstract}

Keywords: VAR, monetary policy, misspecification, output gap, technology shocks.

JEL: E 30, E 52.

\footnotetext{
${ }^{*}$ Stockholm School of Economics, Department of Economics. Box 6501, SE-11383, Stockholm, Sweden. Phone: +4687369270 . Fax: +468 313207. E-mail: nepgi@hhs.se. I would like to thank David Domeij, Martin Eichenbaum, Eric Leeper, Lars Ljungqvist, and Anders Vredin for comments, and Charles Evans for providing data. A special thank to Paul Söderlind and Lars Svensson for comments and discussions. Financial help from the Wallanders Foundation is gratefully acknowledged.
} 


\section{Introduction}

A vast literature has produced a reference framework for VAR analysis of monetary policy. ${ }^{1}$ This reference VAR includes a commodity price index. The first VAR studies showed that omitting a commodity price and taking a short interest rate as the policy instrument produced a response of the price level to contractionary monetary policy shocks which was positive for many quarters, a finding that took the name of price puzzle. Sims (1992) proposed a rationale for the puzzle, and a way to fix it. His conjecture was that the information set available to policy makers may include variables useful in forecasting future inflation that the econometrician has not considered. If the VAR forecast of inflation is in fact a poor one, the VAR will mistakenly identify as shocks movements in the instrument of policy which are in fact endogenous responses to signals of future inflation, hence the finding that prices increase after a contractionary monetary policy shock (henceforth $M P$ shock). ${ }^{2}$ Sims himself (1992) and later studies building on this suggestion have found that the puzzle disappears in the US, at least to a large extent, when the VAR is extended to include a commodity price index, a variable useful in forecasting inflation.

Besides solving the price puzzle, the inclusion of a commodity price changes the overall picture of monetary policy, in that the response of output to a $M P$ shock is smaller and $M P$ shocks are less important in the variance decomposition of output and of the federal funds rate (the policy instrument). Based on these results, Leeper, Sims and Zha (1996) warn that the exclusion of a commodity price can result in serious misspecification.

\footnotetext{
${ }^{1}$ For a summary of this literature see Christiano, Eichenbaum and Evans (1998) or Leeper, Sims and Zha (1996). For a thorough presentation of the framework VAR for monetary policy analysis, see Favero (2000).

${ }^{2}$ Another explanation of the puzzle, proposed by Barth and Ramey (2000), suggests that rising prices following a monetary contraction need not be a puzzle if monetary policy operates not only through demand effects, but also through supply effects. This may be a plausible explanation for prices moving above average for a few months, but arguably not for three or four years, as Sims (1992) finds when he exludes a commodity price from his VAR.
} 
But while no one wants a price puzzle in their VAR, eliminating it sometimes comes at a cost since the models monetary economists work with do not include a commodity price. Of course the models are not meant to be complete representations of reality, and if monetary authorities do react to information not incorporated in the models, so much worse for the models. Nevertheless, having to include a commodity price in the VAR can be disturbing if a researcher is trying to bring a model to the data and she is interested in identifying all shocks, or anyway more than just $M P$ shocks. For example, how are we to interpret the structural shocks if the VAR has two price levels, say CPI and commodity prices, but the theoretical model only has one? Adding variables to the VAR to solve the price puzzle makes interpretation and identification of shocks other than the $M P$ shock more problematic and less model-driven. This paper argues that this situation may be avoidable.

The paper explores the possibility that the price puzzle may be due to something other than the omission of a variable useful in forecasting inflation (such as a commodity price). It shows that a wide class of models produce a price puzzle when subjected to a seemingly innocent misspecification common in applied research: only output is used in applications while theory also speaks of the output gap. The intuition is that since the output gap is omitted from the inflation equation, the interest rate spuriously appears in that equation with a positive coefficient, because the interest rate reacts positively to output gap increases and thus acts as a proxy for that omitted variable.

The rest of the paper proceeds as follows. Section 2 presents a model for monetary policy analysis (Svensson, 1997), which incorporates in a simple form some key features of more complex models and admits a triangular identification scheme in the order: potential output (or output gap), output, inflation and interest rate. Taking the model as the data generating process $(D G P)$, this section derives analytical results on the consequences of estimating a three vari- 
able VAR that includes output but not the output gap. Among other things, a price puzzle emerges and the variance of the $M P$ shocks is overestimated. The impact of a $M P$ shock on output is also overestimated. The consequences of the misspecification are also shown through impulse responses, giving more color to the analytical results.

These results rest on very mild assumptions on the transmission mechanism of monetary policy, mainly that monetary policy affects output with a lag and prices with a longer lag, a feature for which there is strong empirical support and wide agreement. Therefore the results extend to a rich class of models (Section 2.3), which include microfounded and forward-looking models such as Clarida, Gali and Gertler (1999), Svensson (2000a), and Christiano, Eichenbaum and Evans (2001).

Section 3 takes the theory to the data, using as output gap a measure of capacity utilization produced by the Federal Reserve Board. A three variable VAR in the order: output gap, inflation and federal funds rate, is compared to a VAR including output rather than the output gap. The second VAR produces a large price puzzle, the first none. In the first VAR monetary policy is more endogenous and accounts for much less of the forecast error variance of output. Overall, the results produced by the first VAR are closer to those implied by theory and by larger VARs that include a commodity price. The results are shown to be robust to a variety of changes. Section 3.1 estimates a four variable VAR (derived from the model) in the order: potential output, output, inflation, federal funds rate, and finds that all results are unaltered, as predicted. Section 4 argues that the commodity price index does not solve the price puzzle because it is useful in forecasting inflation, but rather because it is correlated with the output gap. Section 5 concludes. 


\section{A simple model for monetary policy analysis: Svensson (1997)}

The main theme of this paper is that the omission from the VAR of a measure of output gap is predicted to generate a price puzzle in a class of models defined by mild assumptions on the transmission mechanism of monetary policy. While this result applies to a rich class of forward-looking models, to obtain analytical solutions I will work with a backward-looking model due to Svensson (1997). Section 2.3 defines the features a model should incorporate to produce a price puzzle when incorrectly estimated, mainly that monetary policy affect output with a lag and inflation with a longer lag. There it is argued that the empirical support for such features is very strong, and that several recent DSGE models have incorporated them in an attempt to improve empirical performance, including Rotemberg and Woodford (1997), Clarida, Gali and Gerlter (1999), Svensson (2000a), and Christiano, Eichenbaum and Evans (2001).

Svensson (1997) is a model designed to capture some key features of the transmission mechanism of monetary policy. The same model is used in Rudebusch and Svensson (1999), in Judd and Rudebusch (1998), in Hansen and Sargent (2000a, 2000b, 2001) and, extended to a small open economy, in Ball (1999). A forward-looking version appears in Clarida, Gali and Gertler (1999) and in Svensson (2000a and 2000b). Romer (2000) presents the same model as an improvement over the traditional $I S$ - $L M$. The model consists of an $I S$ equation, a Phillips curve and a Taylor rule obtained from the monetary authority's optimization problem. This core three-equation structure is shared by many recent New-Keynesian models for monetary policy analysis. A distinctive feature of the model is that it incorporates delays in the transmission of monetary policy. Monetary policy can affect output only with a lag. Output, in turn, affects inflation with a lag. Since the transmission from policy action to prices 
goes through output variations, monetary policy affects prices with two lags.

The $I S$ relation is given by

$$
y_{t+1}^{g}=\beta_{y} y_{t}^{g}-\beta_{r}\left(i_{t}-\pi_{t}\right)+\epsilon_{t+1}^{A D},
$$

where $i_{t}$ is a short term interest rate set by the monetary authority, $y^{g}$ is the output gap, defined as $y_{t}^{g}=Y_{t}-Y_{t}^{N}$, where $Y_{t}$ is the $\log$ of output and $Y_{t}^{N}$ the $\log$ of natural (or "potential") output. Natural output is assumed to follow an exogenous $\mathrm{AR}(1)$ process $^{3}$

$$
Y_{t+1}^{N}=\rho Y_{t}^{N}+\epsilon_{t+1}^{N}
$$

The Phillips curve is modelled as

$$
\pi_{t+1}=\pi_{t}+\alpha_{y} y_{t}^{g}+\epsilon_{t+1}^{C P} .
$$

All shocks are $i{ }^{4}{ }^{4}$ They are labelled: aggregate demand shock, technology shock and cost-push shock. Denote their standard deviations by $\sigma_{A D}, \sigma_{N}$, $\sigma_{C P}$. The model is supplemented by a loss function for the monetary authority of the standard type

$$
L_{t}=E_{t} \sum_{i=0}^{\infty} \beta^{i}\left[\lambda\left(y_{t+i}^{g}\right)^{2}+\left(\pi_{t+i}-\pi^{*}\right)^{2}\right] .
$$

The solution takes the form of a Taylor rule (See Svensson (1997) for the closedform solution. Since the model is backward-looking the discretionary solution and the commitment solution are the same):

$$
i_{t}=\gamma_{\pi} \pi_{t}+\gamma_{y} y_{t}^{g}
$$

A monetary policy shock can be added by assuming that the Taylor rule is not followed deterministically. In that case, the shock $\epsilon^{M P}$ with std $\sigma_{M P}$ is added to the Taylor rule.

\footnotetext{
${ }^{3}$ Svensson (1997) makes no assumption about potential ouput. I follow Svensson (2000a and 2000b) in assuming an AR(1) process.

${ }^{4}$ The assumption of iid shocks is not particularly restrictive, as more lags can be added to equations (1) to (3) without any difficulty.
} 


\subsection{The correct identification}

$A D$ shocks affect output but not inflation contemporaneously while $M P$ shocks affect neither output nor inflation contemporaneously. Technology shocks increase output contemporaneously, leaving output gap, inflation and interest rate unchanged (the extension of Section 2.3 can accomodate technology shocks that affect all variables). The model delivers a three variable VAR with triangular identification in the order: output gap, inflation, interest rate (output gap and inflation can be reversed). Four variable formulations are also admissible, with any two of output, output gap, natural output, appropriately ordered. However, the model does not justify a three variable VAR including output, inflation and interest rate, which is the core of VARs that researchers have estimated in practice. $^{5}$

\subsection{From the VAR implied by theory to the empirical VAR, taking a false step}

Let the $D G P$ be given by equations $(1)-(5)$. The Taylor rule is assumed deterministic for simplicity (all results generalize to the case $\sigma_{M P}>0$ : the Appendix shows the form taken by the system if $\sigma_{M P}>0$, and a simulation for this case appears later in this section). Suppose that a researcher estimates a VAR including: output, inflation and interest rate (identified in the same order) but not the output gap. ${ }^{6}$ What are the effects of this common and seemingly innocent change?

I start investigating the consequences of this misspecification by relating the true structural moving average representation to the one recovered by the misspecified VAR. To avoid mixing problems of misspecification and of parameter

\footnotetext{
${ }^{5}$ Some exceptions are Rotemberg and Woodford (1997), Leichter and Walsh (1999) and Rudebusch and Svensson (1999).

${ }^{6}$ This group of three variables, with this same ordering, plus a commodity price index ordered after prices, is the core of the framework VAR model for monetary policy analysis (see, for example, Bagliano and Favero (1998) and Favero, 2000).
} 
uncertainty due to small sample size, assume that the sample is large. The $D G P$ has a $\operatorname{VAR}(1)$ representation

$$
A_{0} X_{t}=A_{1} X_{t-1}+\epsilon_{t}
$$

which can be inverted to obtain the moving average representation of the $D G P$

$$
X_{t}=\sum_{i=0}^{\infty} D_{i} \epsilon_{t-i}
$$

where

$$
\begin{aligned}
X_{t}^{\prime}= & \left\{Y_{t}^{N}, Y_{t}, \pi_{t}, i_{t}\right\} \quad \epsilon_{t}^{\prime}=\left\{\frac{\epsilon_{t}^{N}}{\sigma_{N}}, \frac{\epsilon_{t}^{A D}}{\sigma_{A D}}, \frac{\epsilon_{t}^{C P}}{\sigma_{C P}}\right\} \quad V C V\left(\epsilon_{t}\right)=I \\
D_{0}= & {\left[\begin{array}{ccc}
\sigma_{N} & 0 & 0 \\
\sigma_{N} & \sigma_{A D} & 0 \\
0 & 0 & \sigma_{C P} \\
0 & \gamma_{y} \sigma_{A D} & \gamma_{\pi} \sigma_{C P}
\end{array}\right] }
\end{aligned}
$$

The researcher is estimating a VAR in $Y, \pi, i^{7}$, working under the (erroneous) assumption that the moving average representation for the structural residuals is given by (asterisks denote the misspecified system):

$$
Z_{t}=\sum_{i=0}^{\infty} D_{i}^{*} \epsilon_{t-i}^{*}
$$

where $Z_{t}^{\prime}=\left\{Y_{t}, \pi_{t}, i_{t}\right\}$. The researcher identifies the system by assuming that $D_{0}^{*}$ has a lower triangular structure (the system of equations is assumed recursive). Since $D_{0}^{*} D_{0}^{* \prime}=\sum$, where $\sum$ is the variance-covariance matrix of the reduced form residuals, the recursive assumption implies that $D_{0}^{*}=\operatorname{Cholesky}\left(\sum\right)$. The researcher will then interpret $D_{0}^{*}$ as

$$
D_{0}^{*}=\left[\begin{array}{ccc}
\sigma_{A D}^{*} & 0 & 0 \\
b_{21} & \sigma_{C P}^{*} & 0 \\
\gamma_{y}^{*} \sigma_{A D}^{*} & \gamma_{\pi}^{*} \sigma_{C P}^{*} & \sigma_{M P}^{*}
\end{array}\right]
$$

${ }^{7}$ Throughout the paper I refer to the VAR in output, inflation and interest rate as "misspecified VAR". 
If $\sigma_{M P}=0$, the exclusion of $Y^{N}$ produces no loss of fit in any equation, a result driven by the deterministic form of the Taylor rule that allows to retrieve $Y^{N}$ (and thus $y^{g}$ ) with no error as a linear combination of the three variables of the system. Therefore the misspecified VAR produces optimal forecasts of inflation at all time horizons, excluding the possibility that the standard explanation for the price puzzle may be relevant in this setting. Consequently

$$
\sum=D_{0}^{*} D_{0}^{*^{\prime}}=\left[D_{0} D_{0}^{\prime}\right]_{2}^{4}
$$

where $\left[D_{0} D_{0}^{\prime}\right]_{2}^{4}$ is the $3 \times 3$ matrix obtained deleting the first row and the first column of $D_{0} D_{0}^{\prime}$ (which involve covariances with potential output).

$$
\begin{aligned}
{\left[D_{0} D_{0}^{\prime}\right]_{2}^{4}=} & {\left[\begin{array}{ccc}
\sigma_{N}^{2}+\sigma_{A D}^{2} & 0 & \gamma_{y} \sigma_{A D}^{2} \\
& \sigma_{C P}^{2} & \gamma_{\pi} \sigma_{C P}^{2} \\
& \gamma_{y}^{2} \sigma_{A D}^{2}+\gamma_{\pi}^{2} \sigma_{C P}^{2}
\end{array}\right]=D_{0}^{*} D_{0}^{*^{\prime}}=} \\
= & {\left[\begin{array}{ccc}
\sigma_{A D}^{* 2} & \sigma_{A D}^{*} b_{21} & \gamma_{y}^{*} \sigma_{A D}^{* 2} \\
& \sigma_{C P}^{* 2}+b_{21}^{2} & b_{21} \gamma_{y}^{*} \sigma_{A D}^{*}+\gamma_{\pi}^{*} \sigma_{C P}^{* 2} \\
& & \gamma_{y}^{* 2} \sigma_{A D}^{* 2}+\gamma_{\pi}^{* 2} \sigma_{C P}^{* 2}+\sigma_{M P}^{* 2}
\end{array}\right] }
\end{aligned}
$$

The relations between the actual and estimated shocks are straightforwardly obtained from the equalities in (7). $b_{21}$ is correctly set to zero, since $\sigma_{A D}^{*} b_{21}=0$. It follows that:

1. $\sigma_{A D}^{* 2}=\sigma_{N}^{2}+\sigma_{A D}^{2}$. The variance of the labelled $A D$ shock is the sum of the variances of the $A D$ shock and of the technology shock. The importance of $A D$ shocks in the variance decomposition of output is overestimated.

2. $\sigma_{A D}^{* 2}=\sigma_{A D}^{2}+\sigma_{N}^{2}$ and $\gamma_{y} \sigma_{A D}^{2}=\gamma_{y}^{*} \sigma_{A D}^{* 2}$ imply $\frac{\gamma_{y}}{\gamma_{y}^{*}}=\frac{\sigma_{A D}^{2}+\sigma_{N}^{2}}{\sigma_{A D}^{2}}>1$, that is the output gap coefficient in the Taylor rule is underestimated. Some simple algebra gives $\gamma_{y} \sigma_{A D}-\gamma_{y}^{*} \sigma_{A D}^{*}=\gamma_{y} \sigma_{A D}\left(1-\frac{\sigma_{A D}}{\sqrt{\sigma_{A D}^{2}+\sigma_{N}^{2}}}\right)>0$. This means that the intensity of the response of the monetary authority to a one std $A D$ shock is underestimated even though the std of $A D$ shocks is overestimated. The intuition is that some unforecasted 
movements in output are due to technology shocks, to which monetary policy does not respond. Since the misspecified VAR registers a small average reaction of the interest rate to unforecasted output movements, the coefficient $\gamma_{y}$ in the Taylor rule is underestimated. The underestimation grows with $\sigma_{N}$.

3. $\sigma_{C P}^{2}=\sigma_{C P}^{* 2}$, following from the fact that $b_{21}=0$.

4. Finally, the variance of $M P$ shocks is overestimated. To derive the result, start from (7), which sets $\gamma_{y}^{2} \sigma_{A D}^{2}+\gamma_{\pi}^{2} \sigma_{C P}^{2}=\gamma_{y}^{* 2} \sigma_{A D}^{* 2}+\gamma_{\pi}^{* 2} \sigma_{C P}^{* 2}+$ $\sigma_{M P}^{* 2}$. Use the results obtained so far, namely

(a) $\quad \gamma_{\pi}^{2} \sigma_{C P}^{2}=\gamma_{\pi}^{* 2} \sigma_{C P}^{* 2}$

(b) $\quad \sigma_{A D}^{* 2}=\sigma_{N}^{2}+\sigma_{A D}^{2}$

(c) $\frac{\gamma_{y}}{\gamma_{y}^{*}}=\frac{\sigma_{A D}^{2}+\sigma_{N}^{2}}{\sigma_{A D}^{2}}$

to obtain

$$
\sigma_{M P}^{* 2}=\gamma_{y}^{2} \frac{\sigma_{A D}^{2} \sigma_{N}^{2}}{\sigma_{A D}^{2}+\sigma_{N}^{2}}>0 .
$$

Even though the Taylor rule is deterministic, the VAR finds that the variance of the labelled $M P$ shock is strictly positive. The intuition is that since the interest rate does not react in the same way to technology and $A D$ shocks, when a movement in output (of a given amount) is observed the VAR will sometimes register a certain change in the interest rate (when the movement is caused by an $A D$ shock) and sometimes a different change (when caused by a technology shock) and will be tricked into interpreting this as random behavior of the monetary authority. ${ }^{8}$ If $\sigma_{M P}>0$, the right-end-side of equation (8) gives a lower bound for $\sigma_{M P}^{* 2}-\sigma_{M P}^{2}$. Notice that if $\sigma_{N}=0$, all misspecifications disappear, as they should since in that case $y_{t}^{g}=Y_{t}$.

\footnotetext{
${ }^{8}$ In this model the interest rate does not react at all to technology shocks, but the intuition applies more generally, as long as technology and $A D$ shocks do not have the same impact on output and the interest rate.
} 
I now use the result that $\sigma_{M P}^{*}>0$ to prove that the misspecified system will display a price puzzle. The strategy is to derive the coefficients of the inflation equation in the misspecified VAR.

Use the Taylor rule in (5) to obtain an expression for the output gap

$$
y_{t}^{g}=\frac{1}{\gamma_{y}}\left(i_{t}-\gamma_{\pi} \pi_{t}\right)
$$

and substitute it into the Phillips relation. This yields

$$
\pi_{t+1}=\left[1-\alpha_{y} \frac{\gamma_{\pi}}{\gamma_{y}}\right] \pi_{t}+\frac{\alpha_{y}}{\gamma_{y}} i_{t}+\epsilon_{t+1}^{C P} .
$$

Equation (10) is both the inflation equation in the VAR and the structural equation of the recursive system, since $b_{21}=0$ (see (7)) implies that $Y_{t+1}$ has a zero coefficient. If $\sigma_{N}=0$, it follows that $y_{t}^{g}=Y_{t}$, so there is no misspecification and (10) is equivalent to

$$
\pi_{t+1}=\pi_{t}+\alpha_{y} Y_{t}+\epsilon_{t+1}^{C P} .
$$

$Y_{t}, \pi_{t}$, and $i_{t}$ are then perfectly collinear and choosing between (10) and (11) is a matter of taste. On the other hand, if $\sigma_{N}>0$, no other autoregressive representation fits as well as (10). Therefore OLS will retrieve (10). The reason why $i_{t}$ appears with a positive coefficient in (10) is that movements in the interest rate help retrieve movements in the output gap, which is omitted. Since $\alpha_{y} / \gamma_{y}>0$ and output does not appear in the equation, the impact of a the retrieved $M P^{*}$ shock (which causes $i_{t}$ to be higher than forecasted) on inflation is estimated to be zero contemporaneously and positive at one lag. In other words, a positive response of inflation to a contractionary $M P$ shock (a price puzzle) at lag one is guaranteed as long as the variance of the retrieved $M P$ shocks is estimated to be strictly positive, which will be the case if $\sigma_{N}>0$ (see equation (8)). The magnitude of the puzzle at lag one is given by $\frac{\alpha_{y}}{\gamma_{y}} \sigma_{M P}^{*}$, so it grows with the variance of technology shocks (see equation (8)). If the 
econometrician is ordering the interest rate first she will obtain an even more pronounced price puzzle, since $\sigma_{M P}^{*}$ is obviously larger and the inflation equation will show a positive coefficient on the contemporaneous value of the interest rate, so the impulse response to a contractionary $M P$ shock will show inflation raising immediately. ${ }^{9}$

To gain further understanding of the puzzle, it is useful to show that the misspecified $M P^{*}$ shocks are positively correlated with the true $A D$ shocks and negatively correlated with the true technology shocks.

In the DGP, the one-step-ahead forecast error is given by

$$
i_{t+1}-E_{t} i_{t+1}=\gamma_{y} \epsilon_{t+1}^{A D}+\gamma_{\pi} \epsilon_{t+1}^{C P},
$$

while the one-step-ahead forecast error in the misspecified model is given by

$$
i_{t+1}-E_{t}^{*} i_{t+1}=\gamma_{y}^{*} \epsilon_{t+1}^{* A D}+\gamma_{\pi}^{*} \epsilon_{t+1}^{* C P}+\epsilon_{t+1}^{* M P}
$$

Asterisks denote the shocks obtained from the misspecified VAR. Since the assumption that $\sigma_{M P}=0$ implies $E_{t} i_{t+1}=E_{t}^{*} i_{t+1}$, we can equate the righthand-sides and use the results just obtained, namely $\gamma_{\pi} \epsilon_{t+1}^{C P}=\gamma_{\pi}^{*} \epsilon_{t+1}^{* C P}, \epsilon_{t+1}^{* A D}=$ $\epsilon_{t+1}^{A D}+\epsilon_{t+1}^{N}$ to obtain as expression for $\epsilon^{* M P}$,

$$
\epsilon_{t+1}^{* M P}=\left(\gamma_{y}-\gamma_{y}^{*}\right) \epsilon_{t+1}^{A D}-\gamma_{y}^{*} \epsilon_{t+1}^{N} .
$$

Since $\operatorname{cov}\left(\epsilon_{t+1}^{A D}, \epsilon_{t+1}^{N}\right)=0$ by assumption, using $\frac{\gamma_{y}}{\gamma_{y}^{*}}=\frac{\sigma_{A D}^{2}+\sigma_{N}^{2}}{\sigma_{A D}^{2}}>0$ gives

$$
\begin{gathered}
\operatorname{cov}\left(\epsilon_{t+1}^{* M P}, \epsilon_{t+1}^{A D}\right)=\left(\gamma_{y}-\gamma_{y}^{*}\right) \sigma_{A D}^{2}>0, \\
\operatorname{cov}\left(\epsilon_{t+1}^{* M P}, \epsilon_{t+1}^{N}\right)=-\gamma_{y}^{*} \sigma_{N}^{2}<0 .
\end{gathered}
$$

These results provide further intuition for the origin of the price puzzle: the misspecified monetary policy shocks are positively correlated with the true

\footnotetext{
${ }^{9}$ The existence of a price puzzle does not depend crucially on the fact that the central banker can observe inflation and the output gap contemporaneously (see Section 2.3).
} 
aggregate demand shock, which in turn raise inflation with a lag. Since at lag one the true monetary policy shocks cannot affect inflation, only the spurious part is active at lag one, so we are certain to find a price puzzle. Moreover, monetary policy shocks are spuriously correlated with technology shocks. This means that the misspecified impulse response of output to a contractionary monetary policy shock is contaminated by the response of output to a negative technology shock. If potential output is more persistent than the output gap, the response of output to a monetary policy shock will be longer lived than the true one.

There are more potentially erroneous conclusions that can be derived from the misspecified system. To illustrate them, I obtain the reduced form equation for output in the misspecified system. Start with the $I S$ equation (1) and eliminate $y_{t+1}^{g}, y_{t}^{g}$ using the definition, $y_{t}^{g}=Y_{t}-Y_{t}^{N}$. Move $Y_{t+1}^{N}$ to the righthand-side and substitute it using (2). This leaves $\epsilon_{t+1}^{N}$ and $Y_{t}^{N}$ on the righthand-side. Finally, eliminate $Y_{t}^{N}$ from the right-hand-side by rearranging (9) as

$$
Y_{t}^{N}=Y_{t}-\frac{1}{\gamma_{y}}\left(i_{t}+\gamma_{\pi} \pi_{t}\right)
$$

which gives the equation for output in the misspecified model

$$
Y_{t+1}=\rho Y_{t}+\left[\left(\rho-\beta_{y}\right) \frac{\gamma_{\pi}}{\gamma_{y}}+\beta_{r}\right] \pi_{t}-\left[\left(\rho-\beta_{y}\right) \frac{1}{\gamma_{y}}+\beta_{r}\right] i_{t}+\epsilon_{t+1}^{A D}+\epsilon_{t+1}^{N} .
$$

If $\rho>\beta_{y}$, as plausible, the effect of a given interest rate shock on output one step ahead is overestimated, since the coefficient attached to $i_{t}$ is larger than $\beta_{r}$.

The derivation of (10) and (18) assumed that the Taylor rule is deterministic. The Appendix shows the form taken by the system if $\sigma_{M P}>0$, and a simulation for this case appears later in this section. If $\sigma_{M P}>0$, the misspecified system $(Y, \pi, i)$ is no longer $\operatorname{VAR}(1)$, but $\operatorname{VARMA}(2,1)$. This implies that 
the econometrician who is selecting a lag length for a VAR is likely to choose a VAR with more than one lag, and will produce sub-optimal fit and forecasts even is she estimates a $\operatorname{VARMA}(2,1)$.

A more complete picture of the consequences of the misspecification can be gained from looking at impulse responses. The experiment is as follows. Each graph plots the response of output or inflation or interest rate to a shock in the theoretical economy together with the response to the same shock in the misspecified three variable VAR (output, inflation, interest rate).

The model parameters are set as in Ball (1999): $\alpha_{y}=0.4, \beta_{y}=0.8, \beta_{r}=1$. Reflecting the idea that potential output is a highly persistent process, $\rho=0.98$. The standard deviations are $\sigma_{A D}=\sigma_{C P}=\sigma_{N}=1$. For ease of comparison, the parameters in the Taylor function are not set to the optimal value in each case, but are kept constant at $\gamma_{y}=0.5, \gamma_{\pi}=1.5 .^{10}$ These parameters are kept fixed. The only difference between Figure 1 and Figure 2 is the standard deviation of the true monetary policy shock. In Figure $1 \sigma_{M P}=0$, so all results are analytical. Recall that the differences between theoretical and misspecified responses cannot be accounted for by parameter uncertainty. The response of output to a labelled $A D$ shock is higher than the true one upon impact and more persistent thereafter, while the response of the interest rate to an $A D$ shock is underestimated. In the low-right corner, notice that the estimated std of a $M P$ shock, which is zero in the $D G P$, is a substantial 0.35 . Therefore in the variance decomposition of all variables the role of $M P$ shocks, which is truly zero, is estimated to be positive. The price puzzle has warning proportions. The response of output to a misspecified $M P$ shock is highly persistent, reflecting the fact that the misspecified $M P$ shocks are negatively correlated with the true technology shocks.

\footnotetext{
${ }^{10}$ The optimal value of the parameters of the Taylor function has a closed form solution given in Svensson (1997).
} 
OUTPUT to AD shock

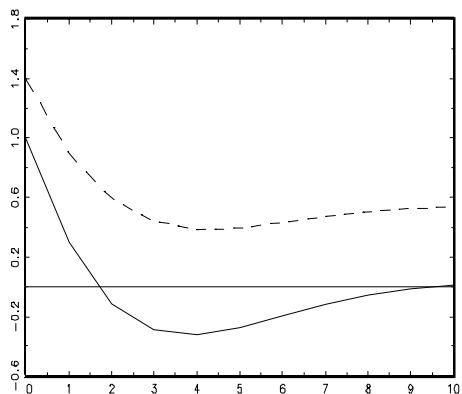

OUTPUT to CP shock

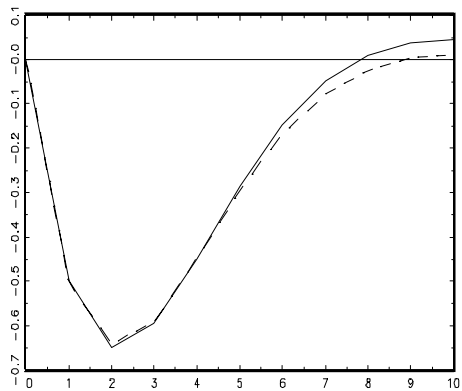

OUTPUT to MP shock

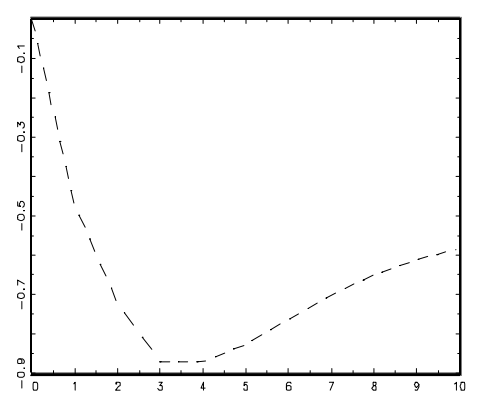

INFL to AD shock

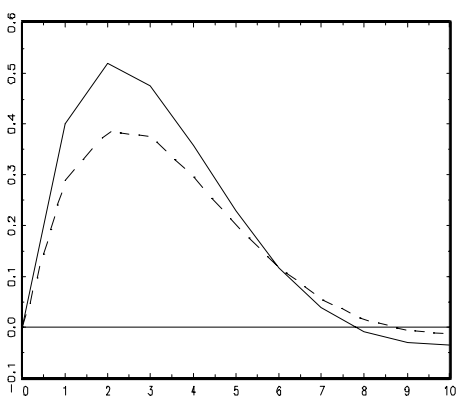

INFL to CP shock

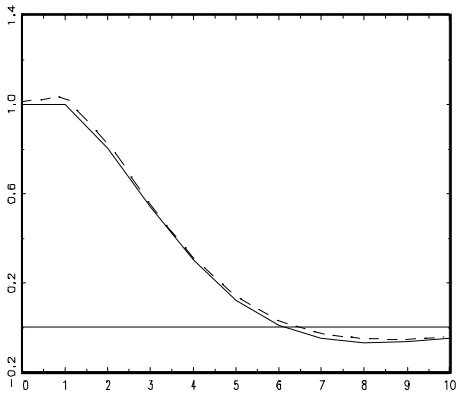

INFL to MP shock

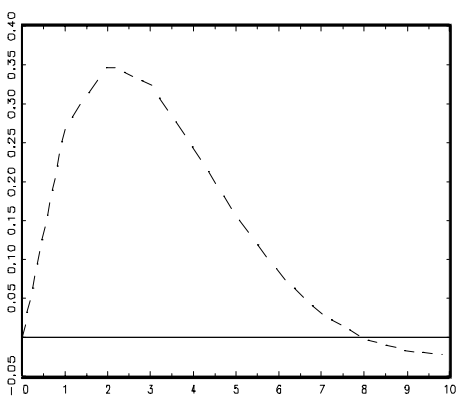

FFR to AD shock

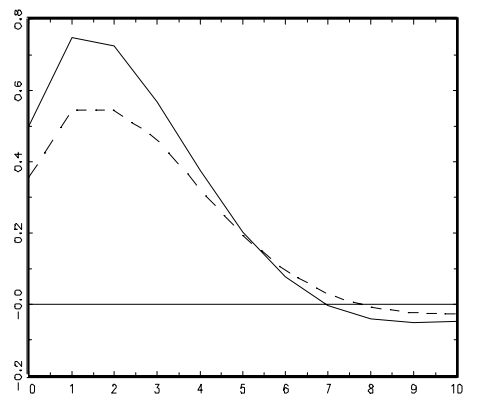

FFR to CP shock

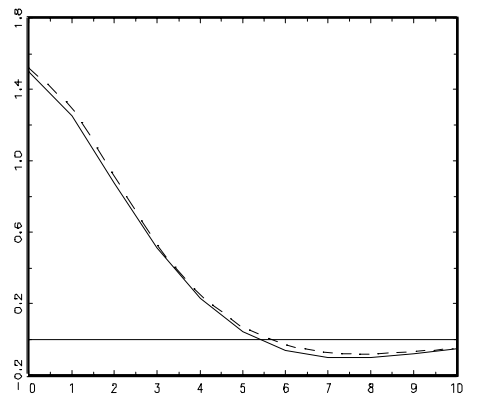

FFR to MP shock

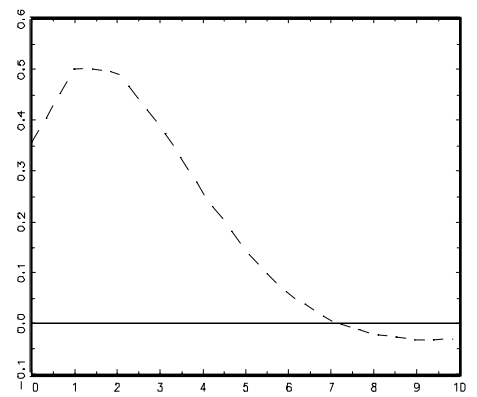

Figure 1: True impulse responses (solid line) and impulse responses from misspecified VAR (dashed line). $\sigma_{M P}=0$. 
In the second experiment a stochastic element is added to the behavior of the monetary authorities by setting $\sigma_{M P}=1$. The results are displayed in Figure 2. As previously argued, the misspecified system is no longer $\operatorname{VAR}(1)$ when $\sigma_{M P}>0$, and impulse responses for the misspecified VAR have to be obtained numerically if we are to give the misspecified model its best chance. ${ }^{11}$ Portmanteau test of residual correlation is first passed at four lags, so a VAR(4) is fit to the misspecified system. If less than four lags are chosen, the misspecifications maintain the same qualitative pattern but become larger. The response of the interest rate to an $A D$ shock is underestimated, again as expected. Responses to $M P$ shocks are once again those that display the most obvious misspecification. On the low-right corner, the std of the $M P$ shock is overestimated. The price puzzle is substantial and can now be confronted with the true behavior of inflation in response to a $M P$ shock. As for the response of output to a $M P$ shock, not only is the size of the response overestimated, but the response is much longer lived than the true one (the reason being that the retrieved $M P$ shocks are negatively correlated with the true technology shocks). These results extend without surprises to different combinations of $\rho, \sigma_{N}, \sigma_{M P}$.

In fact, the main results are valid if potential output is a non-constant deterministic function of time while the only exogenous variable in the misspecified VAR is a constant. In that case equation (10) does not change, while $\sigma_{M P}^{*}>0$, since no combination of the included variables is perfectly correlated with the output gap: therefore there will be a price puzzle. Simulations using deterministic trends have shown that the effects of $M P$ shocks in this case look much like in Figure 2.

\footnotetext{
${ }^{11}$ The missspecified impulse responses are obtained by fitting a VAR on data generated by the DGP. The first 500 observations are not used in estimation. The VAR is estimated on 10000 observation to eliminate parameter uncertainty.
} 
OUTPUT to AD shock

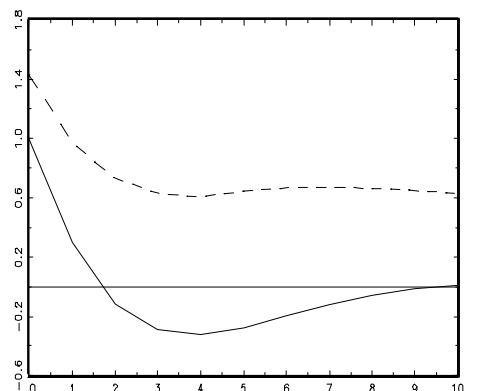

OUTPUT to CP shock

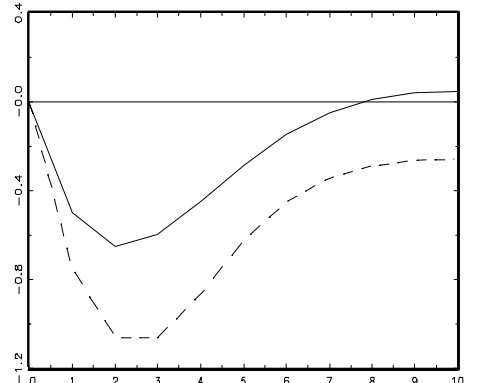

OUTPUT to MP shock

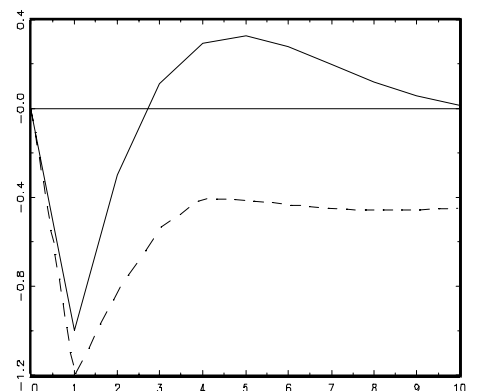

INFL to AD shock

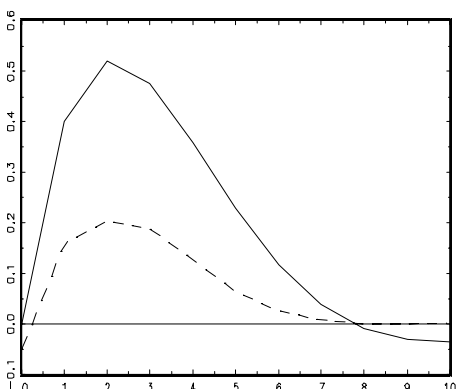

INFL to CP shock

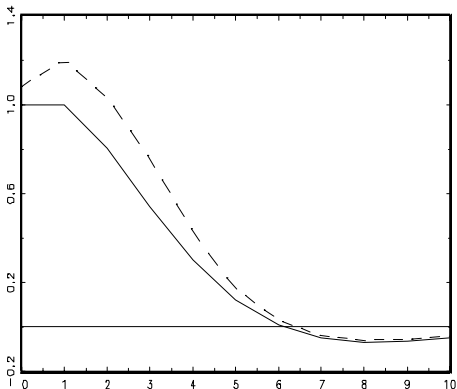

INFL to MP shock

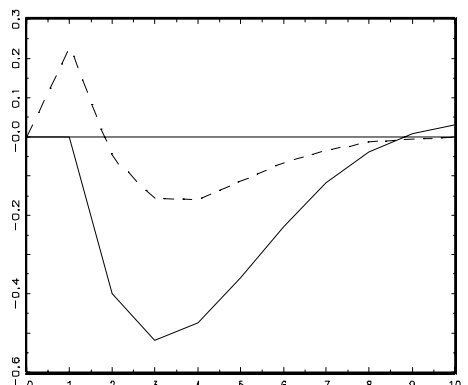

FFR to AD shock

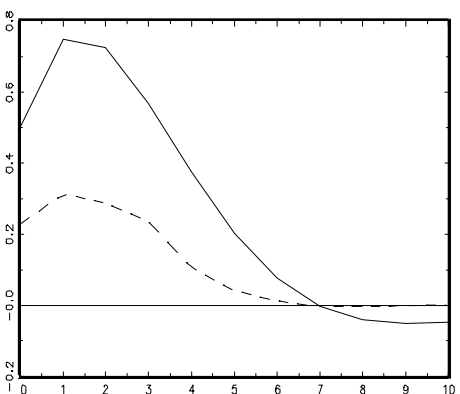

FFR to CP shock

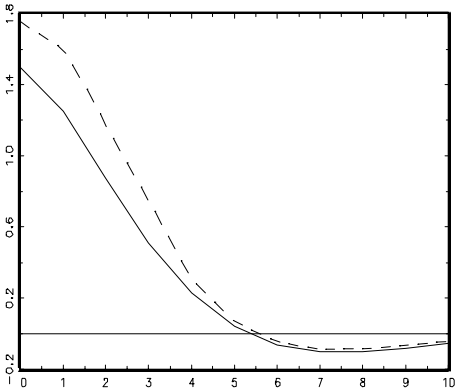

FFR to MP shock

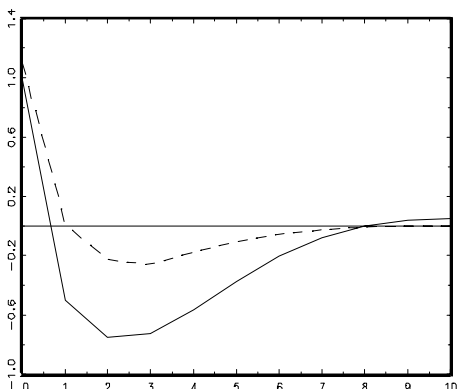

Figure 2: True impulse responses (solid line) and impulse responses from misspecified $\operatorname{VAR}(4)$ (dashed line). $\sigma_{M P}=1$. 


\subsection{Robustness of the main results and forward-looking models}

The adoption of a simple backward-looking model has allowed us to derive analytical solutions. However, the result of a spurious appearance of a price puzzle holds in a wide class of models, which include microfounded and forward-looking models. The models in this class have a reduced-form solution characterized by $^{12}(i)$ inflation responds with a lag and positively to the output gap $(i i)$ the monetary policy authority can affect inflation with no less than two lags (iii) the output gap appears with a positive coefficient in the monetary policy function and $(i v) y_{t}^{g}$ cannot be reduced to a linear combination of: a constant, $Y_{t}, \pi_{t}$, and varibles dated $t-1$ or earlier.

Overestimation of $M P$ shocks follow from the fact that the output gap appears in the true policy function

$$
i_{t+1}=\gamma_{y} y_{t+1}^{g}+\ldots
$$

Since the output gap is omitted in the misspecified model, assumption (iii) implies that the fit of the equation must deteriorate (notice that $i$ and $y^{g}$ are both dated $t+1$, so the forecasting power need not deteriorate). Therefore $\sigma_{M P}^{*}>0$ even if $\sigma_{M P}=0$.

The price puzzle generates from the fact that the policy instrument appears in the misspecified inflation equation to pick up the role of the omitted output gap. If the reduced VAR form (only variable dated $t$ or earlier in the righthand-side) of the true inflation equation is

$$
\pi_{t+1}=\alpha_{y} y_{t}^{g}+\ldots .
$$

and monetary policy cannot affect inflation contemporaneously or at one lag, then, rearranging (19) and plugging it in (20), we'll find a price puzzle feature in the misspecified inflation equation, since $\frac{\partial \pi_{t+1}}{\partial i_{t}}=\frac{\alpha_{y}}{\gamma_{y}}>0$ and $\sigma_{M P}^{*}>0$.

\footnotetext{
${ }^{12}$ These conditions are sufficient, not necessary.
} 
The key assumption that $M P$ shocks affect output with a lag and inflation with a longer lag is strongly supported in empirical work, including VAR studies, and is commonly incorporated in macro models for monetary policy analysis (like the MPS macro model of the US). For example, Christiano, Eichenbaum and Evans (1998) include this feature of the transmission mechanism among the 'stylized facts' produced by the VAR literature on monetary policy, and use it to cast doubt on the Lucas supply curve, which implies a different timing. Svensson (2000a) writes that "Both VAR evidence and practical central-bank experience indicate that there is a shorter lag for ... aggregate demand than for domestic inflation". ${ }^{13}$ Clarida, Gali and Gertler (1999) agree "...since much of the available evidence suggests a lag of six to nine months in the effect of a shift in the interest rate on output. The lag in the effect of inflation is around a year and a half". ${ }^{14}$ The same opinion can be found in Ball (1999).

While some highly stylized microfounded models allow monetary policy to have immediate effects on all variables, several researchers have recently incorporated the timing of monetary policy implied by Svensson (1997) in microfounded, forward-looking models. For example, Clarida, Gali and Gertler (1999) suggest the following modification of the basic New-Keynesian framework ${ }^{15}$, with the motivation that "...there is strong empirical justification for incorporating delays in the effect of policy":

$$
\begin{aligned}
y_{t+1}^{g} & =\beta_{y} y_{t}^{g}+\left(1-\beta_{y}\right) E_{t} y_{t+2}^{g}-\beta_{r}\left(i_{t}-E_{t} \pi_{t+1}\right)+\epsilon_{t+1}^{A D} \\
\pi_{t+1} & =\gamma \pi_{t}+\alpha_{x} y_{t}^{g}+(1-\gamma) E_{t} \pi_{t+2}+\epsilon_{t+1}^{C P} \\
i_{t} & =\gamma_{\pi} \pi_{t}+\gamma_{y} y_{t}^{g},
\end{aligned}
$$

where lags of all variables could be included in the policy function. Their model satisfies all the conditions needed to generate a price puzzle (unless, of course,

\footnotetext{
${ }^{13}$ Page 12 in the Working Paper version.

${ }^{14}$ Page 47 in the Working Paper version.

${ }^{15}$ Refer to their Section 6.
} 
potential output is constant). Svensson (2000a) also provides a microfounded, forward-looking model which incorporates the same key feature of the transmission mechanism. Finally, Rotemberg and Woodford (1997) assume information delays or pre-commitement to action in their model to produce delays in the transmission of monetary policy.

Moreover, the conditions for a price puzzle stated above are sufficient, not necessary. In particular, inflation may start moving before the second period after a $M P$ action: the result will go through as long as the initial movement is sufficiently small. For example, in a Calvo framework without informational delays, the initial response of inflation will be small if prices are sufficiently sticky (i.e. the probability of being able to change prices is sufficiently small). To take another example of forward-looking Phillips curve, consider Fuhrer and Moore (1995). Their set-up will also produce small initial reponses of inflation to a $M P$ shock, if a sufficiently small proportion of wages is re-contracted in each period. Finally, Christiano, Eichenbaum and Evans (2001) estimate a complex microufounded, forward-looking model embedding several real and nominal frictions. In their model, monetary policy cannot affect output and inflation within the period by assumption. After estimating the model, they conclude that "...the model suceeds in accounting for the inertial response of inflation. Indeed, there is no noticeable rise in inflation until roughly three years after the shock. Third, the model generates a very persistent response in output, with the peak response occurring after one year". ${ }^{16}$

Notice that the assumptions needed to produce a price puzzle can be satisfied also by models that:

- Have a fair amount of contemporaneous reactions. For example, in Svensson (2000a) a negative technology shock decreases prices with a lag and

\footnotetext{
${ }^{16}$ Page 26.
} 
the output gap and the interest rate contemporaneously. ${ }^{17}$

- Do not allow the central bank to observe prices and the output gap contemporaneously. This may require some slightly stronger assumptions on the transmission lags. In Svensson (1997), for example, it would then be sufficient to assume that monetary policy affects inflation (sizeably) only after three periods.

- Include a more complex loss function for the monetary authority, interest rate smoothing being a particularly interesting example.

- Do not assume that marginal costs are proportional to the "output gap".

This last point deserves some discussion. While this paper is focusing on the concept of deviations from potential output, its results are not confined to models what work with that concept. What is driving the result is the presence of a cyclical variable to which inflation and monetary policy respond, but which is not included in the VAR. This leads to the interest rate appearing in the inflation equation of the VAR to capture movements in the omitted cyclical variable.

\section{Solving the puzzle on US data}

The strategy to test the hypothesis presented so far is straightforward:

1. Estimate a three variable VAR (the misspecified VAR) including: output ( $\log$ of real GDP), CPI inflation, federal funds rate (same identification ordering).

2. Estimate the same VAR but with a measure of output gap rather than output. (I call this VARgap).

\footnotetext{
${ }^{17}$ Canova and Pina (1999) have an example of misspecification arising when the econometrician imposes short-run restrictions while the DGP does not have enough restrictions on contemporaneous responses to identify any shock.
} 
3. Compare the impulse responses of the two VARs and check whether they behave as predicted by the analysis of Section 2 .

In relation to the second point, a VAR including: a measure of output gap, inflation and federal funds rate is estimated in Rudebusch and Svensson (1999) and it does not produce a significant price puzzle. One of the contributions of this paper is to rationalize their finding.

As a measure of the output gap I use the series of capacity utilization built by the Federal Reserve Board. ${ }^{1819}$ The response of a variables to a given shock in the two VARs are plotted on the same graph. A VAR(3) was estimated in all cases. ${ }^{20}$ Figure 3 plots impulse responses for the two VARs estimated on the sample 1970:1 2000:2 (unless otherwise stated all figures are produced with a VAR(3) on the sample 1970:1 2000:2). 90\% error bands for VARgap are included.

Variance decomposition for VARgap and for the misspecified VAR are presented in Figure 4 and Figure 5 respectively.

The reader is invited to compare Figures 3 and 2: in all nine cases the theoretical model correctly predicts whether the impulse response of VARgap lies above or below the impulse response of the misspecified VAR. The following

\footnotetext{
${ }^{18}$ Data description:

Capacity utilization is seasonally adjusted. It is available at FRED data base, http://www.stls.frb.org/fred/data/business/cumfg

The federal funds rate series is also taken from FRED, aggregated from monthly (averages), available at http://www.stls.frb.org/fred/data/business.

All other series are from the IMF database: GDP at constant prices (base year 1995), sa, CPI (all items), sa, were logged before estimation. All series used in this paper are available in an E-views workfile (please request them at nepgi@hhs.se).

${ }^{19}$ Since capacity utilization is expressed as a percentage of full capacity for the manufacturing sector, a scale adjustment was used to account for the fact that industrial production (manufacturing) is more volatile than GDP. Therefore the series used in estimation is capacity $\times 0.5$. The number 0.5 is the result of the following computations. I assume that the output gap for GDP (in logs) is a multiple of the output gap in manufacturing. That is

$y_{t}^{g}=\alpha y_{t}^{g, \text { manufacturing }}$, implying that $\alpha=\operatorname{std}\left(y_{t}^{g}\right) / \operatorname{st} d\left(y_{t}^{g, \text { manufacturing }}\right)$. Using data on sa industrial production and taking std of deviations from linear trends, I estimate $\alpha=0.5$. A very similar result is obtained by comparing the standard deviations of the growth rates.

${ }^{20}$ The Schwarz and HQ criteria both select two lags for VARgap and, respectively, two and four lags for the misspecified VAR.
} 
OUTPUT to AD shock

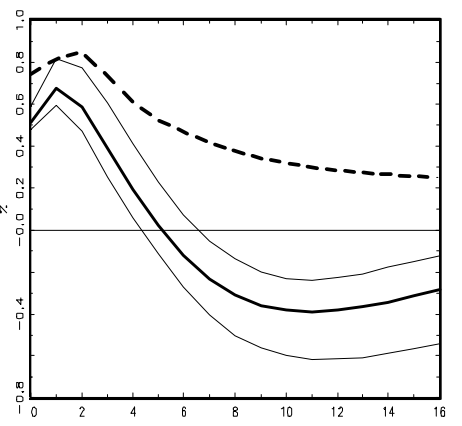

OUTPUT to CP shock

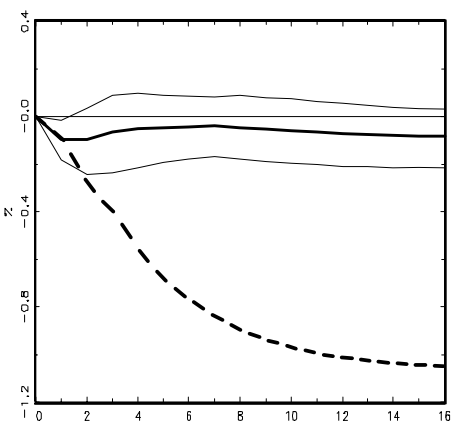

OUTPUT to MP shock

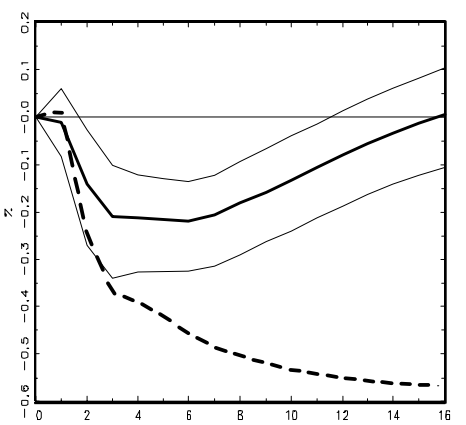

INFL to AD shock

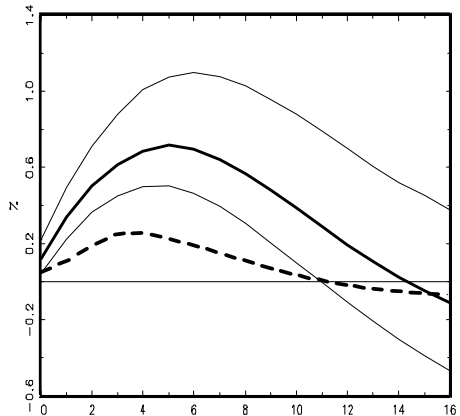

INFL to CP shock

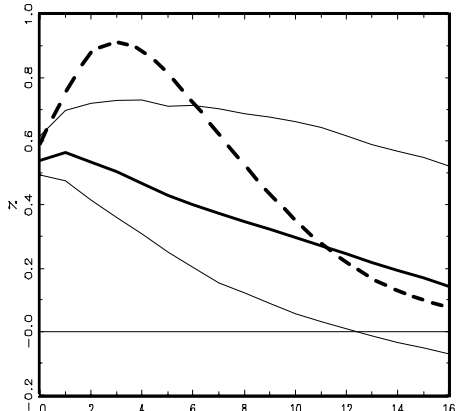

INFL to MP shock

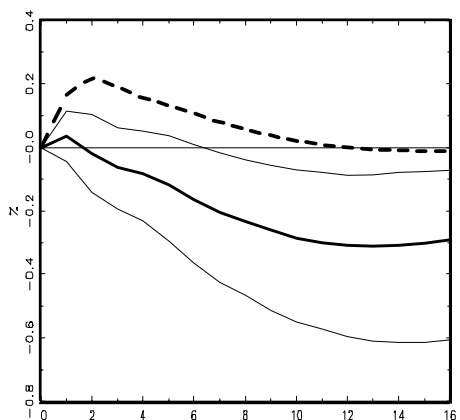

FFR to AD shock

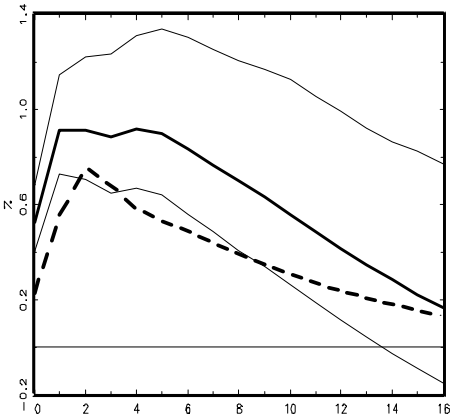

FFR to CP shock

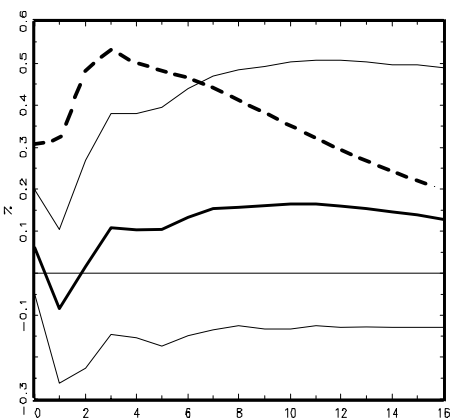

FFR to MP shock

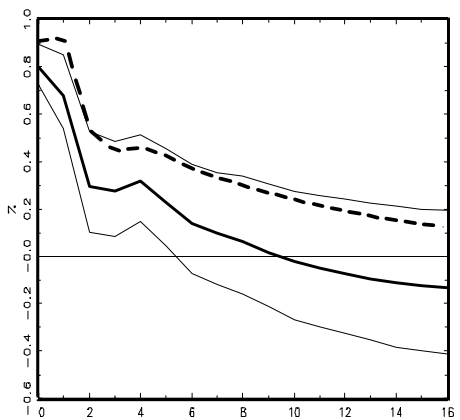

Figure 3: Impulse responses for misspecified VAR (real GDP, inflation and federal funds rate. Dashed line) compared with those from VARgap (output gap rather than output. Solid line). 90\% error bands for VARgap (computed as in Doan, 1992). Sample 1970Q1 2000Q2 

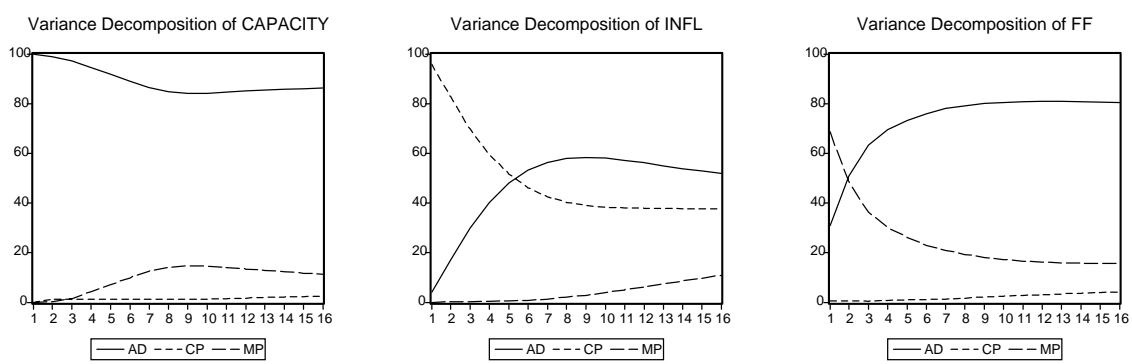

Figure 4: Variance decomposition for VARgap.
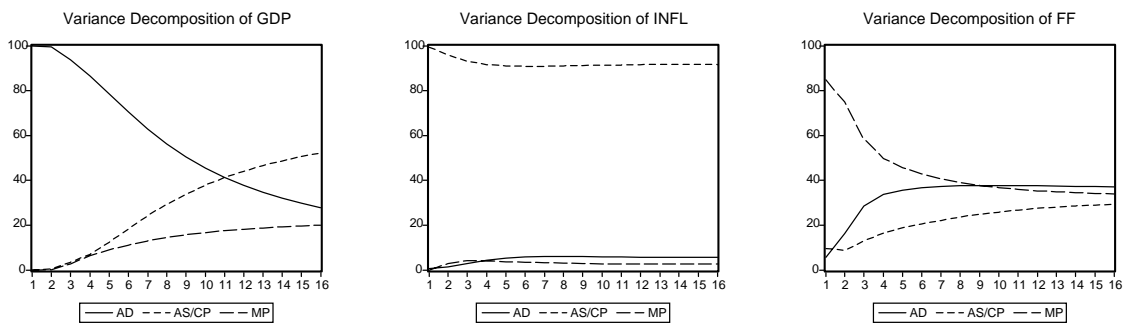

Figure 5: Variance decomposition for the misspecified VAR.

results are all predicted by the analysis of Section 2 :

1. There is no price puzzle in VARgap, while there is a huge price puzzle in the misspecified VAR.

2. The response of the federal funds rate to an $A D$ shock is higher in VARgap, even though the $A D$ shock has a lower standard deviation.

3. The responses of output (gap) to all shocks are shorter-lived in VARgap.

4. The std of $M P$ shocks is $12 \%$ lower in VARgap, and standard deviations of the inflation equation and of the federal funds rate equation (in reduced form) are $7 \%$ and $11 \%$ lower. Therefore VARgap is expected to produce superior forecasts (since it fits better with the same number of parameters). 
5. Monetary policy looks much more endogenous as the percentage of the federal fund rate forecast error variance due to $M P$ shocks is substantially reduced in VARgap.

6. The share of $M P$ shocks in the variance decomposition of output gap in VARgap is less (one half after 16 periods) then in the decomposition of output in the misspecified VAR.

7. The share of $M P$ shocks in the variance decomposition of output in the misspecified VAR grows with the forecast horizon, as predicted (the reason being that the labelled $M P$ shocks are correlated with technology shocks). In contrast, $M P$ shocks in VARgap display no such behavior (the result doesn't change at forecast horizons longer than four years).

8. The inflation equation in the two VARs take the form suggested by Section 3 (refer to equations 3 and 11): in VARgap the lagged values of capacity utilization are highly significant, while the lags of the federal funds rate are insignificant (the F-test for their exlusion has p-value 0.39), while in the "misspecified" VAR the lagged values of output are insignificant (pvalue 0.38 ) and lags of the federal funds rate figure prominently (p-value 0.02. The signs of significant variables are those suggested by theory in all cases).

\subsubsection{Robustness of the results}

I checked the robustness of the results to different lag length structure (range 18) and starting sample dates (1960 and 1980). Switching capacity and inflation in the identification ordering also has little effect on either impulse responses or variance decompositions, as predicted by the model. Using the log of prices instead of inflation does not change any result in this and later sections.

The following alternative measures of output gap have been considered: log 
deviations from a linear and from a quadratic trend, the $\mathrm{CBO}$ measure of output gap, ${ }^{21}$ unemployment, and, for the fun of it, the cycle component of HP filtered $\log$ output. ${ }^{22}$ All the main results are fairly robust to the choice of the output gap proxy. Not all measures work as well though: using capacity utilization (and HP filter), nearly identical results are obtained for every reasonable choice of lags (range 1-8), while deviations from linear and quadratic trends (which remain highly persistent) produce a price puzzle for some choices of lags (four or higher); unemployment and the $\mathrm{CBO}$ (the least successful variable) measure sizeably reduce the entity of the puzzle, but do not eliminate it. Capacity utilization produces the best fit in both the inflation and the interest rate equation.

Several researchers ${ }^{23}$ have noticed that a commodity price index does not solve the price puzzle on the pre-1979 sample. VARgap is not as robust on the 1966-1979 sample, in the sense that some specifications do produce a sizeable price puzzle. Including both output and the output gap reduces the puzzle, possibly because capacity is a less efficient proxy of the output gap in this sub-sample. For purposes of comparison with previous literature, I estimate a VAR(4) including capacity, real gdp (in logs), the GDP deflator (in logs) and the federal funds rate on the sample 1966Q1-1979Q1. This specification produces "well-behaved" responses (refer to Figure 6).

\subsection{Extending the VAR to include output}

So far three variable VARs have been estimated. Of course there is no reason why output should be excluded from the VAR as long as a measure of output gap is included. In this case technology shocks become part of the picture. The

\footnotetext{
${ }^{21}$ The Congressional Budget Office releases a measure of real potential output, from which I construct the measure of output gap used in the VAR as: $\ln ($ real GDP)-ln(CBO potential output).

${ }^{22}$ The HP filter is two-sided, therefore the filtered data should not be used in regression analysis, since they will lead to inconsistent estimates. However, the same is true, strictly speaking, of linear and quadratic detrending, which are commonly used, and some researchers may nonetheless be curious about the results given by both filters.

${ }^{23}$ See, for instance, Hanson (2000), and Barth and Ramey (2000).
} 



Figure 6: Responses to a $M P$ shock, with \pm 2 std error bands (analytic). VAR(4) including: capacity, log real gdp, log gdp deflator, federal funds rate. Sample 1966Q1-1979Q1.

Svensson model then predicts that all responses to shocks other than technology shocks should be the same as in the three variable VARgap. Two orderings suggested by the model are: output gap, output, inflation, federal funds rate, and potential output, output, inflation, federal funds rate. I choose the second because it has the advantage of being correct even if technology shocks do affect the output gap, as in Svensson (2000a), conditional, of course, on a good measure of potential output. It turns out that all results are robust to the choice of using output gap instead of potential output. ${ }^{24}$ I construct potential output (logged) from real GDP and the measure of capacity used in the previous section. ${ }^{25}$

The impulse response functions are shown in Figure 7 (error bands include plus and minus two std). The following results stand out:

1. The inclusion of output does not produce any change worth noticing on any

\footnotetext{
${ }^{24}$ The first ordering retrieves the shocks in the order: $A D$, technology, $C P, M P$. The second in the order: technology, $A D, C P, M P$.

${ }^{25} \log$ of natural output is defined as $y^{n}=y-($ capacity/100), where capacity is obtained by multiplying the original series by 0.5 , as motivated in Section 3 .
} 
of the responses (the comparison is with the three variable VARgap). This is encouraging evidence that the shocks in VARgap had been identified correctly.

2. The response of output to a technology shock is very similar to the response of natural output, while inflation and the federal funds rate have small and insignificant responses to technology shocks. That is, technology shocks do not affect the output gap, supporting the identification: output gap, output, inflation, federal funds rate. In fact, results from the two alternative identifications are fully compatible. Impulse responses and variance decomposition indicate that natural output is an exogenous random walk with drift.

3. Variance decompositions (not reported) also confirm the results obtained for the three variable VARgap. The share of technology shocks in the decomposition of inflation and of the federal funds rate is negligible. The share of technology shocks in the variance decomposition of output is substantial at all horizons (almost always above 50\%).

4. Section 2 showed that, in the theoretical framework, the $M P^{*}$ shocks retrieved from the misspecified VAR are positively correlated with the true $A D$ shocks and negatively correlated with the true technology shocks. Using technology shocks and $A D$ shocks taken from the four variable VAR and $M P^{*}$ shocks from the misspecified VAR, this prediction can be tested and is in fact correct: $\operatorname{corr}\left(\epsilon_{A D}, \epsilon_{M P}^{*}\right)=0.35, \operatorname{corr}\left(\epsilon_{N}, \epsilon_{M P}^{*}\right)=-0.32$.

5. The impulse responses at long lags (five years or longer, not shown) show that the long run effect of technology shocks on output is one to one, while all other shocks have a zero long run effect. Thus, although the identification is based on short-run restrictions, the results are fully consistent 

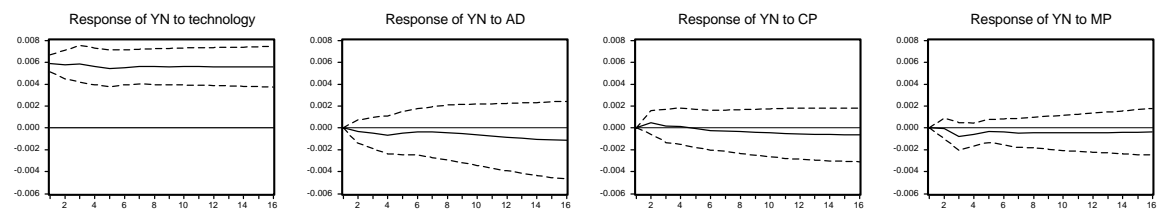

Response of $Y$ to technology

Response of $\mathrm{Y}$ to $\mathrm{AD}$

Response of $Y$ to $C P$
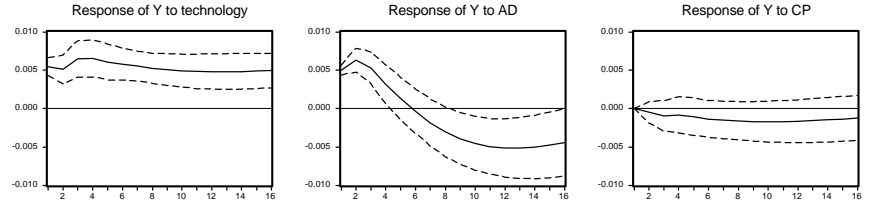

Response of $Y$ to $\mathrm{MP}$

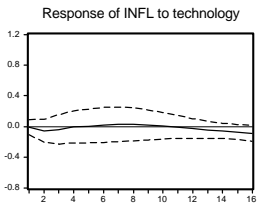

Response of INFL to AD

Response of INFL to CP
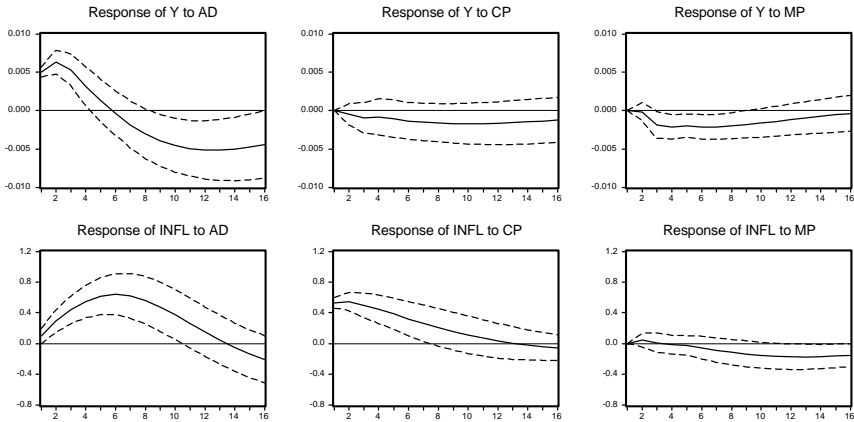

Response of INFL to MP

Response of $\mathrm{FF}$ to technology

Response of $F F$ to $A D$

Response of $\mathrm{FF}$ to $\mathrm{CP}$

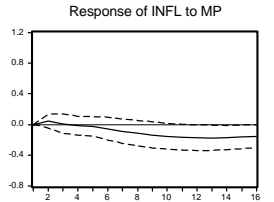

Response of $\mathrm{FF}$ to $\mathrm{MP}$
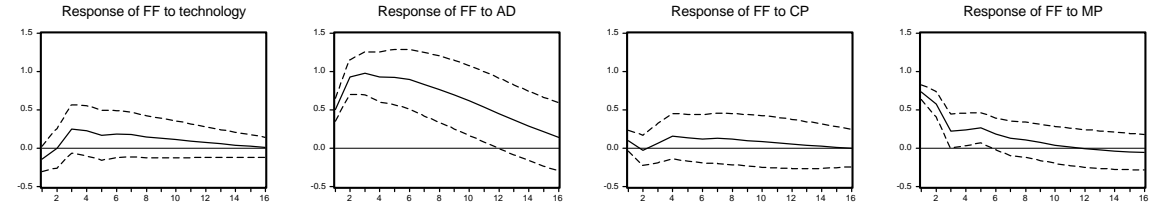

Figure 7: Impulse responses for the VAR: natural output, output, inflation, federal funds rate. Error bands (analytical) include plus and minus two standard deviations.

with the hypothesis that only technology shocks have a long-run impact on output.

\section{Why does a commodity price index solve the price puzzle? Discriminating between two al- ternative explanations}

This section argues that the commodity price index solves the price puzzle mainly because it contains useful information about the output gap, not because it is useful in forecasting inflation. PcomCEE ${ }^{26}$ and capacity utilization do tend

\footnotetext{
${ }^{26}$ I call PcomCEE the index used by Christiano, Eichenbaum and Evans (1998). This index does not display a trend (so it is meaningful to talk of its correlation with other stationary variables).
} 
to move together (correlation 0.58 on the sample 1970:1-1998:4). ${ }^{27}$

The standard explanation implies that the price puzzle should disappear when a good leading indicator of inflation is included in the VAR. Since commodity prices have added value in predicting inflation, commodity prices should solve the price puzzle. The puzzle does almost completely disappear in a four variable VAR with the standard ordering: output, inflation, PcomCEE, federal funds rate.

But other powerful leading indicators of inflation should also go at least some way in solving the puzzle, if this theory is correct. For example, a long interest rate should react quickly to news of future inflation. The slope of the term structure, which the VAR is free to capture since a short and a long interest rate are included, is known to have forecasting power for inflation. This suggested using the yield on ten year government bonds instead of commodity prices. The results are surprising: the price puzzle is very large, as large as if this variable is omitted.

Next I estimate a four variable VAR including (in this order): output, inflation, inflation forecast, federal funds rate. Inflation forecast is the forecast of average inflation during the next four quarters. The forecasts are produced with a VAR (which includes PcomCEE) estimated recursively. ${ }^{28}$ The resulting forecast series is then included in the four variable VAR in place of commodity price. The forecast do have some value, since in response to a forecast shock inflation grows monotonously and the response is significant at the $5 \%$ level for several quarters. Based on the standard explanation of the puzzle, the inclusion

\footnotetext{
27 The publication of the commodity price index used in Christiano, Eichenbaum and Evans (1998) has been discontinued around 1996. The series was used by the Department of Commerce as a leading indicator. Data up to 1998Q4 have been kindly provided by Charles Evans, who constructed the last few data points following the procedure used by the DOC.

${ }^{28}$ The variables are: inflation, $\log$ of real output, commodity price index, federal funds rate and the three year yield on government bills. The VAR is first estimated on the sample 1960:1 to $1970: 1$ and the forecast is produced for average inflation during the periods 1970:2 to 1971:1. The VAR is then re-estimated adding one observation, another forecast is produced and so on.
} 

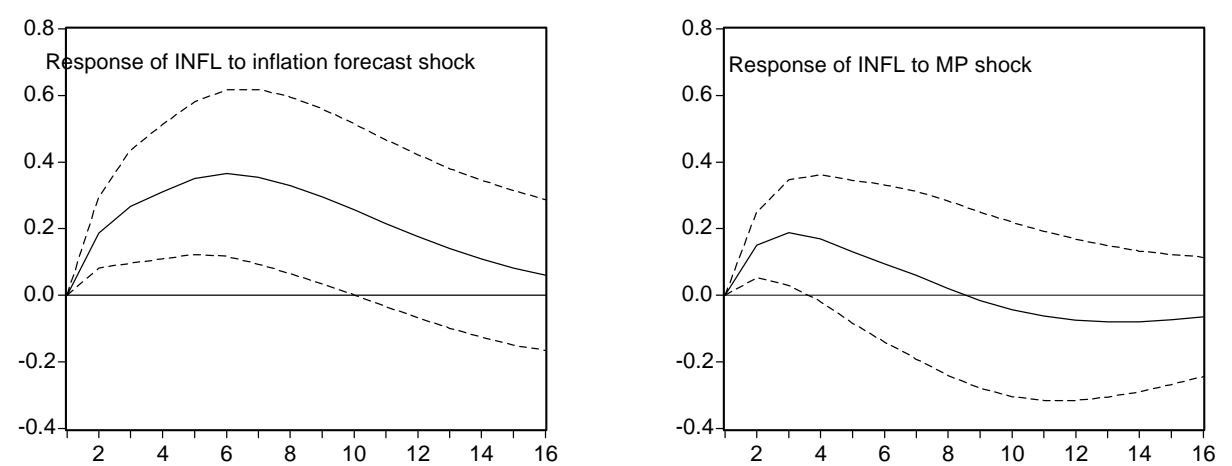

Figure 8: Response of inflation to news of future inflation and to a MP shock in a VAR including the forecast of future inflation from the ASA/NBER survey.

of the inflation forecasts in the VAR should eliminate or at least mitigate the puzzle. In fact it doesn't help a bit. The response of prices to a $M P$ shock (not reported) is unaffected. The same exercise is repeated with a forecast from a different source, the ASA/NBER Survey. ${ }^{29}$ I take the mean across forecasters of the forecast of average inflation during the next four quarters (the same variable as before). The response of inflation to an expectation shock is highly significant (the error bands in Figure 8 are for $\pm 2 s t d$ ), but the price puzzle remains substantial in both size and time extension.

These figures do not change if the forecast of future inflation is substituted with future inflation itself (one or two quarters ahead), with a little white noise error added to avoid a singular variance-covariance matrix. ${ }^{30}$ Also, they do not change much using a standard "price of commodity" (as opposed to the leading indicator used by Christiano, Eichenbaum and Evans, 1998), or the

\footnotetext{
${ }^{29}$ Also known as the Survey of Professional Forecasters. Joutz and Stekler (2000) find that "The FED forecasts (of GNP and GNP deflator) were not significantly different from the predictions of ASA/NBER surveys". Since forecasts of CPI inflation are only available from 1981, I take the forecasts of GNP deflator inflation. Data and details are available at http://frb.libertynet.org/files/spf

${ }^{30}$ I thank Martin Eichenbaum for suggesting this further check.
} 
price of intermediate goods or industrial prices. These result complement those obtained by Barth and Ramey (2000) and by Hanson (2000), who "find little correlation between an ability to forecast inflation and an ability to resolve the price puzzle". ${ }^{31}$

In order to further test the claim, I test the following two hypothesis (the statements are for the null):

1. Once capacity is included in the Fed reaction function, PcomCEE is redundant.

2. Once PcomCEE in included in the Fed reaction function, capacity is redundant.

The testing procedures start with a model that nests both: federal funds rate regressed on a constant, three lags of itself, contemporaneous and lagged (three lags) values of inflation, output, PcomCEE, capacity (sample 1970:1 1998:4). The p-value for the F-statistic that commodity prices are redundant is 0.18 . On the other hand, the hypothesis that capacity is redundant is clearly rejected (p-value 0.0003). In fact a better fit is obtained in the equation above excluding both output and PcomCEE than excluding capacity only.

This paper suggests that variables useful in mitigating or solving the price puzzle should be highly cyclical. For example, the correlation between the unemployment rate ${ }^{32}$ and capacity utilization is 0.74 . In fact, the unemployment rate used instead of capacity does a rather good job at solving the price puzzle, with inflation negative after four lags.

\footnotetext{
${ }^{31}$ Abstract.

${ }^{32}$ Standardized unemployment rate, sa, OECD data base.
} 


\section{Conclusions}

This paper argues that the finding of a positive response of inflation to a contractionary $M P$ shock (price puzzle) in VARs designed for monetary policy analysis may not be due to monetary authorities having better forecasts than those produced by the VAR. Rather, it may be due to the omission of a measure of output gap in the VAR. This omission is shown to produce a price puzzle in a wide class of models that would display no such effect if correctly estimated and identified. The key requirement is that monetary policy affects output with a lag and inflation with a longer lag, a hypothesis strongly supported by empirical evidence and incorporated in several recent DSGE models. Using a model due to Svensson to derive analytical results, it is shown that the omission of output gap also leads to overestimation of the variance of monetary policy shocks and to incorrect identification of the response of monetary policy to all the shocks in the economy. Moreover, the importance of monetary policy shocks in the variance decomposition of output is overestimated, and their effects are estimated to be longer than they actually are. The spurious appearance of a price puzzle is shown to extend to a wide class of microfounded and forward-looking models.

When the implications of the theoretical analysis are tested on US data all the main predictions are confirmed: the comparison of two three-variable VARs, one of which includes output rather than the output gap, gives the predicted results in terms of impulse responses and variance decompositions. In particular, $M P$ shocks do not cause a price puzzle, have shorter-lived effects on output and less relevance in the variance decomposition of all variables. Thus very small VARs (three of four variables) can reproduce the results of much larger systems concerning the effects of $M P$ shocks, while facilitating identification of other shocks if the model provides enough restrictions.

Finally, it is argued that the effectiveness of a commodity price index in 
solving the puzzle does not depend on its usefulness in predicting inflation. Rather, it is probably due to its fairly high correlation with the most popular measures of output gap. Using a measure of output gap (or potential output) is not only theoretically more appealing, but also leads to a better fit of the reaction function. 


\section{Appendix: the correct and misspecified rep- resentation if the DGP has monetary policy shocks}

The correct VAR.

$$
\left[\begin{array}{l}
y_{t+1}^{g} \\
\pi_{t+1} \\
i_{t+1}
\end{array}\right]=\left[\begin{array}{ccc}
1 & 0 & 0 \\
0 & 1 & 0 \\
\gamma_{y} & \gamma_{\pi} & 1
\end{array}\right]\left[\begin{array}{ccc}
\beta_{y} & \beta_{r} & -\beta_{r} \\
\alpha_{y} & 1 & 0 \\
0 & 0 & 0
\end{array}\right]\left[\begin{array}{c}
y_{t}^{g} \\
\pi_{t} \\
i_{t}
\end{array}\right]+\left[\begin{array}{ccc}
1 & 0 & 0 \\
0 & 1 & 0 \\
\gamma_{y} & \gamma_{\pi} & 1
\end{array}\right]\left[\begin{array}{c}
\epsilon_{t+1}^{A D} \\
\epsilon_{t+1}^{C P} \\
\epsilon_{t+1}^{M P}
\end{array}\right]
$$

The misspecified VAR(1)

Use $y_{t}^{g}=Y_{t}-Y_{t}^{N}$ in the previous VAR, expand out the $Y_{t+1}^{N}$ and $Y_{t}^{N}$ terms and use $Y_{t+1}^{N}=\rho Y_{t}^{N}+\epsilon_{t+1}^{N}$.

$$
\begin{aligned}
{\left[\begin{array}{c}
Y_{t+1} \\
\pi_{t+1} \\
i_{t+1}
\end{array}\right]=} & {\left[\begin{array}{ccc}
1 & 0 & 0 \\
0 & 1 & 0 \\
\gamma_{y} & \gamma_{\pi} & 1
\end{array}\right]\left[\begin{array}{ccc}
\beta_{y} & \beta_{r} & -\beta_{r} \\
\alpha_{y} & 1 & 0 \\
0 & 0 & 0
\end{array}\right]\left[\begin{array}{c}
Y_{t} \\
\pi_{t} \\
i_{t}
\end{array}\right]+\left[\begin{array}{c}
-\beta_{y}+\rho \\
-\alpha_{y} \\
-\gamma_{y} \rho
\end{array}\right] Y_{t}^{N}+} \\
& {\left[\begin{array}{ccc}
1 & 0 & 0 \\
0 & 1 & 0 \\
\gamma_{y} & \gamma_{\pi} & 1
\end{array}\right]\left[\begin{array}{c}
\epsilon_{t+1}^{A D}+\epsilon_{t+1}^{N} \\
\epsilon_{t+1}^{C P} \\
\epsilon_{t+1}^{M P}-\gamma_{y} \epsilon_{t+1}^{N}
\end{array}\right] }
\end{aligned}
$$

Eliminate $Y_{t}^{N}$ rearranging the Taylor rule

$$
Y_{t+1}^{N}=Y_{t}-\frac{1}{\gamma_{y}} i_{t}+\frac{\gamma_{\pi}}{\gamma_{y}} \pi_{t}+\frac{1}{\gamma_{y}} \epsilon_{t}^{M P},
$$

to obtain the final representation

$$
\begin{aligned}
{\left[\begin{array}{c}
Y_{t+1} \\
\pi_{t+1} \\
i_{t+1}
\end{array}\right]=} & {\left[\begin{array}{ccc}
\rho & \left(\rho-\beta_{y}\right) \frac{\gamma_{\pi}}{\gamma_{y}}+\beta_{r} & -\left[\left(\rho-\beta_{y}\right) \frac{1}{\gamma_{y}}+\beta_{r}\right] \\
0 & 1-\alpha_{y} \gamma_{\pi} & \frac{\alpha_{y}}{\gamma_{y}} \\
0 & \beta_{r} \gamma_{y}-\beta_{y} \gamma_{\pi}+\gamma_{\pi}-\frac{\alpha_{y}}{\gamma_{y}} \gamma_{\pi}^{2} & -\beta_{r} \gamma_{y}+\beta_{y}-\frac{\alpha_{y}}{\gamma_{y}} \gamma_{\pi}
\end{array}\right]\left[\begin{array}{c}
Y_{t} \\
\pi_{t} \\
i_{t}
\end{array}\right]+} \\
& {\left[\begin{array}{c}
\epsilon_{t+1}^{A D}+\epsilon_{t+1}^{N} \\
\epsilon_{t+1}^{C P} \\
\gamma_{y} \epsilon_{t+1}^{A D}+\gamma_{\pi} \epsilon_{t+1}^{C P}+\epsilon_{t+1}^{M P}
\end{array}\right]+\left[\begin{array}{c}
\rho-\beta_{y} \\
-\alpha_{y} \\
-\gamma_{y} \beta_{y}-\gamma_{\pi} \alpha_{y}
\end{array}\right] \epsilon_{t}^{M P} }
\end{aligned}
$$

If $\sigma_{M P}>0$, a $\operatorname{VAR}(1)$ will have autocorrelated errors. Therefore the econometrician is likely to select a longer lag lenght. It will soon be proved that the myspecified system has a VARMA $(2,1)$ representation. Therefore the misspecified system will have inferior fit and forecasting efficiency than the correctly specified one, even if a $\operatorname{VARMA}(2,1)$ is estimated. ${ }^{33}$

${ }^{33}$ See Lutkepohl (1993), pag. 234. 
Proposition 1 The misspeficied system $Y, \pi, i$ has a VARMA(2,1) representation.

Proof. Write the DGP as

$$
\begin{aligned}
{\left[\begin{array}{cc}
1-\rho L & 0 \\
A_{0-} A_{1} L & B_{0-} B_{1} L
\end{array}\right]\left[\begin{array}{c}
Y_{t}^{N} \\
Z_{t}
\end{array}\right] } & =\left[\begin{array}{c}
\epsilon_{t}^{N} \\
\epsilon_{t}^{Z}
\end{array}\right], \text { or, in compact notation, } \\
F(L) X_{t} & =\epsilon_{t}, \text { where } Z_{t}^{\prime}=\left\{Y_{t}, \pi_{t}, i_{t}\right\}, \epsilon^{Z}=\left\{\epsilon_{t}^{A D}, \epsilon_{t}^{C P}, \epsilon_{t}^{M P}\right\}^{\prime}
\end{aligned}
$$

Where $L$ denotes the lag operator and

$$
A_{0}=\left[\begin{array}{c}
-1 \\
0 \\
\gamma_{y}
\end{array}\right], A_{1}=\left[\begin{array}{c}
\beta_{y} \\
\alpha_{y} \\
0
\end{array}\right], B_{0}=\left[\begin{array}{ccc}
1 & 0 & 0 \\
0 & 1 & 0 \\
-\gamma_{y} & -\gamma_{\pi} & 1
\end{array}\right], B_{1}=\left[\begin{array}{ccc}
\beta_{y} & \beta_{r} & -\beta_{r} \\
\alpha_{y} & 1 & 0 \\
0 & 0 & 0
\end{array}\right] \text {. }
$$

Premultiply both sides of (21) by $F(L)^{-1}$. The resulting system for $Z_{t}$ is

$$
Z_{t}=\left(B_{0}-B_{1} L\right)^{-1}\left(A_{0}-A_{1} L\right)(1-\rho L)^{-1} \epsilon_{t}^{N}+\left(B_{0}-B_{1} L\right)^{-1} \epsilon_{t}^{Z} .
$$

Premultiply both sides by $\left(B_{0}-B_{1} L\right)(1-\rho L)$ and rearrange

$$
Z_{t}=\left(B_{0}^{-1} B_{1}+\rho I\right) Z_{t-1}-\rho B_{0}^{-1} B_{1} Z_{t-2}-\left(A_{0}-A_{1} L\right) \epsilon_{t}^{N}+(1-\rho L) B_{0}^{-1} \epsilon_{t}^{Z},
$$

where $-\left(A_{0}-A_{1} L\right) \epsilon_{t}^{N}+(1-\rho L) B_{0}^{-1} \epsilon_{t}^{Z}$ has a multivariate $M A(1)$ representation of the form $-\left(A_{0}-A_{1} L\right) \epsilon_{t}^{N}+(1-\rho L) B_{0}^{-1} \epsilon_{t}^{Z}=(I+M L) u_{t}, u$ multivariate (three dimensional) white noise (Lutkepohl (1993), pag. 231). 


\section{References}

[1] Bagliano, F. C.and C. A. Favero, 1998, Measuring monetary policy with VAR models: An evaluation, European Economic Review, 42, 1113-1140.

[2] Ball, L., 1999, Policy rules for open economies, in: John B. Taylor, Monetary Policy Rules, (University of Chicago Press, Chicago).

[3] Barth, M. J, and V. A. Ramey, 2000, The cost channel of monetary transmission, NBER Working Paper, 7675.

[4] Blanchard, O. and D. Quah, 1989, The dynamic effects of aggregate demand and supply disturbances, American Economic Review, 79, 655-673.

[5] Canova, F. J. P. Pina, J. P., 1999, Monetary policy misspecification in VAR models, working paper, Universitat Pompeu Fabra, Barcelona. Available at www.econ.upf.es.

[6] Canova, F., 1998a, Detrending and business cycle facts, Journal of Monetary Economics, 41, 475,-512.

[7] Christiano, L.J., M. Eichenbaum and C. L. Evans, 1998, Monetary policy shocks: What have we learned and to what end?, NBER WP \#6400.

[8] Christiano, L.J., M. Eichenbaum and C. L. Evans, 2001, Nominal rigidities and the dynamic effects of a shock to monetary policy, Working Paper.

[9] Clarida, R. and J. Gali, 1994, Sources of real exchange fluctuations: How important are nominal shocks?, Carnegie-Rochester Conference on Public Policy, 41, 1-56.

[10] Clarida, R., J. Gali and M. Gertler, 1999, The Science of monetary policy, Journal of Economic Literature 37, 1661-1707. 
[11] Doan, T. A., 1992, RATS User's manual, Estima.

[12] Favero, C., 2000, Applied macroeconometrics, (Oxford University Press, Oxford).

[13] Fuhrer, J. C., and G. R. Moore, 1995, Monetary policy trade-offs and the correlation between nominal interest rates and real output, American Economic Review 85, 219-239.

[14] Gali, J., 1992, How well does the IS-LM model fit postwar US data?, Quarterly Journal of Economics, 709-738.

[15] Hansen, L. P., and T. J. Sargent, 2000a, Wanting Robustness in Macroeconomics, Working Paper, Stanford University.

[16] Hansen, L. P., and T. J. Sargent, 2000b, Acknowledging Misspecification in Macroeconomic Theory, Working Paper, Stanford University.

[17] Hansen, L. P., and T. J. Sargent, 2001, Elements of Robust Control and Filtering for Macroeconomics, manuscript, Stanford University.

[18] Hanson, M. S., 2000, The "Price Puzzle" reconsidered, Working Paper, Wesleyan University.

[19] Joutz, F and H. O. Stekler, 2000, An evaluation of the predictions of the federal reserve, International Journal of Forecasting, 16, 17-38.

[20] Judd, J. P.and G. D. Rudebush, 1998, Taylor's Rule and the Fed:1970-1997, Economic Review, 3, Federal Reserve Bank of San Francisco.

[21] Leeper, E., C. Sims and T. Zha, 1996, What does monetary policy do?, Brookings Papers on Economic Activity, vol. 2, 1-78. 
[22] Leichter, J. and C. Walsh, 1999, Different economies, common policies: Policy trade-offs under the ECB, working paper. Available at http://econ.ucsc.edu/ ${ }^{\sim}$ walshc.

[23] Lutkepohl, H., 1993, Introduction to multivariate time series analysis, second edition, (Springer-Verlag).

[24] Romer, D., 2000, Keynesian macroeconomics without the LM curve, Journal of Economic Perspectives, 14, 149-169.

[25] Rotemberg, J. J., and M. Woodford, 1997, An optimization-baased econometric framework for the evaluation of monetary policy, NBER Macroeconomics Annual, 297-346.

[26] Rudebusch, G. D. and L. E. O. Svensson, 1999, Policy rules for inflation targeting, in: John B. Taylor Monetary Policy Rules, (University of Chicago Press).

[27] Sims, C., 1992, Interpreting the macroeconomic time series facts: The effects of monetary policy, European Economic Review, 36, 2-16.

[28] Stock, J. H and W. Watson, 1999, Forecasting inflation, Journal of Monetary Economics, 44, 293-336.

[29] Svensson, L. E.O., 1997, Inflation forecast targeting: Implementing and monitoring inflation targets, European Economic Review, 41, 1111-1146.

[30] Svensson, L. E.O., 1999, Inflation targeting as a monetary policy rule, Journal of Monetary Economics, 43, 607-654.

[31] Svensson, L. E.O., 2000a, "Open-economy inflation targeting," Journal of International Economics, 50, 155-183. 
[32] Svensson, L. E.O., 2000b, The zero bound in an open economy: A foolprof way of escaping from a liquidity trap", NBER working paper n.7957. 